\title{
FORMAÇÃO TERRITORIAL DO CEARÁ: DAS 16 VILAS ORIGINAIS AOS 184 MUNICÍPIOS ATUAIS
}

\author{
TERRITORIAL FORMATION OF THE CEARÁ: VILAGES OF 16 ORIGINAL \\ PRESENT TO MUNICIPALITIES 184
}

\author{
LA FORMARCIÓN TERRITORIAL DEL CEARÁ: DE LOS 16 PUEBLOS \\ ORIGINALES A LOS 184 MUNICIPIOS ACTUALES
}

\author{
Vládia da Silva - Universidade Federal do Ceará - Fortaleza - Ceará - Brasil \\ vladia89@yahoo.com.br \\ Francisco Amaro Gomes de Alencar - Universidade Federal do Ceará - Fortaleza - Ceará - Brasil \\ Famaro.ufc@gmail.com
}

\begin{abstract}
Resumo
Este artigo discorre sobre a formação político-administrativa e a divisão territorial do Ceará, atentando para a gênese dos fenômenos que resultaram na criação de novos municípios. Para tanto, recorremos ao processo de ocupação do território cearense, pois compreendemos que os conflitos decorrentes da criação de novas células administrativas têm suas raízes nos primórdios da constituição territorial do Ceará. Sobre esta premissa, objetivamos analisar as relações de poder que estão no cerne das emancipações municipais ocorridas nesse Estado. A metodologia utilizada para alcançar tal fim condiz com um estudo teórico detalhado, com base em uma revisão de literatura sobre a formação territorial do Ceará e o fenômeno de emancipação político-administrativa. De acordo com essa proposta de investigação, chegamos à conclusão de que 0 anseio de emancipação está envolvido em fortes relações que só são passíveis de compreensão mediante o entendimento do que corresponde ao poder, ao território e ao Estado.

Palavras-chave: divisão territorial, emancipações municipais, relações de poder.
\end{abstract}

\section{Abstract}

This article is about the politic-administrative formation and the territorial division of Ceará, speaking of the genesis of the phenomena that resulted in the creation of the new provinces. For this, we turn to the process of occupation of territory in Ceará, because we understand the conflicts resulting from creation of new administrative cells have their roots in the beginnings of the territorial constitution of Ceará. According this premise, we aim to analyze the relations of power are in kernel of the municipal emancipation occurred in these states. The methodology used to achieve these aims consistent in a detailed theoretical study, with a research literature about the territorial formation of Ceará and the phenomena of politic-administrative emancipation. Based in this proposal of investigation we concluded that the wish of emancipation emerges from strong relations that are only possible before the understand what corresponds to the power, to the territory and to the State.

Key words: territorial division, municipal emancipations, relations of power.

\section{Resumen}

En este artículo se discute la formación política y la división territorial administrativa de Ceará, prestando atención a la génesis de los fenómenos que condujeron a la creación de nuevos municipios. Por lo tanto, se recurrió a la ocupación del territorio de proceso de Ceará porque entendemos que los conflictos derivados de la creación de nuevas células administrativas tienen sus raíces en los principios de la constitución territorial de Ceará. Partiendo de esta premisa, el objetivo de analizar las relaciones de poder que se encuentran en el 
corazón de las emancipaciones municipales producidas en este estado. La metodología utilizada para lograr este propósito consiste en un estudio teórico detallado a través de una revisión de la literatura sobre la formación territorial de Ceará y el fenómeno de la emancipación político-administrativa. Sobre la base de esta propuesta de investigación llegó a la conclusión de que el anhelo de emancipación se remoja en relaciones sólidas que son sólo capaces de entender mediante la comprensión de lo que corresponde al poder, el territorio y el Estado. Palabras clave: división territorial, nuevos municipios, las relaciones de poder.

Introdução

Este trabalho é parte da pesquisa de Mestrado em Geografia da Universidade Federal do Ceará e visa discorrer, de forma introdutória, sobre as relações de poder que permeiam o processo de emancipação político-administrativa no estado Ceará. A escolha desse tema para análise se deu mediada pelo interesse nas discussões sobre emancipação e sobre o resgate histórico-geográfico do processo de formação territorial cearense. Paralelamente a isso, existe também o fato de essa temática ser pouco discutida na geografia.

A literatura que discorre sobre este assunto, na maioria dos casos, analisa os processos emancipatórios em escala nacional, ou ainda, em casos bem específicos das regiões Sul e Centro-Oeste do Brasil, enquanto os estudos sobre a independência político-administrativa de municípios que ocorrem no Ceará desde o início de sua formação territorial são ainda pouco investigados. Além disso, as discussões sobre emancipações ganham destaque no campo teórico da Economia e da Administração. A Geografia pouco tem se dedicado a esse assunto, muito embora, ele também seja uma questão geográfica.

Cigolini (2009) classifica as abordagens dos autores que trabalham com essa temática em dois grupos: no primeiro, estão as pesquisas que procuram refletir sobre as razões que estimulam a criação de municípios e, no segundo grupo, estão aqueles que buscam analisar as consequências geradas pelas emancipações.

Dessa forma, neste artigo, procuramos nos desprender das causas e consequências que resultam da criação de municípios, para possibilitar uma análise sobre as estratégias de poder que se territorializam nos processos emancipatórios. Para alcançar tal premissa, é necessário o entendimento do que corresponde ao poder, ao território e ao Estado.

A formação de novos municípios consiste em um fator de ordem política, e, por isso, gera impactos econômicos sobre a população. Isto porque a função primordial de um município é administrar os recur- 
sos públicos, de maneira que se consiga atender às demandas sociais do povo. Sobre esta perspectiva, nada mais natural que o desejo de desmembramento emane dos indivíduos afetados por este processo, o que nem sempre acontece. Na maioria dos casos, os processos de municipalização atendem de forma mais intensa aos anseios políticos de uma pequena elite hegemônica do que a própria necessidade da população local.

À luz dessas questões, esperamos proporcionar um entendimento sobre a criação de municípios no Ceará. A metodologia utilizada para tal fim consiste em um estudo qualitativo com base teórica detalhada mediante uma revisão de literatura sobre o processo de formação territorial cearense e o fenômeno de emancipação político-administrativa.

\section{A ocupação do território cearense}

A ação da Coroa Portuguesa, durante os primeiros séculos da colonização no Brasil, proporcionou, através de tratados como Tordesilhas e Madri, a agregação de espaços que resultaram na configuração de um país com grande extensão territorial. Esse processo refletiu em estratégias políticas de controle do território, caracterizadas pela ocupação de pontos dispersos inicialmente no litoral e, posteriormente, nas áreas interioranas.

No entanto, a apropriação definitiva de terras na colônia brasileira só teve início trinta anos após a colonização, viabilizada pelo sistema de Capitanias Hereditárias, em que a Coroa Portuguesa concedia grandes porções de terras ao donatário, cabendo a este reservar uma parte para si e doar o restante em regime de sesmarias para pessoas cristãs que tivessem condições financeiras de administrar a parte que lhes foram concedidas.

Andrade (1995) afirma que a concessão de sesmarias não conferia o domínio, mas apenas a posse sobre a terra, e, mesmo assim, tal processo desencadeou a ocupação de grandes propriedades, originado os latifúndios brasileiros que perduram até os dias atuais.

Se de início a ocupação se deteve às áreas litorâneas, onde a principal atividade econômica era a cana-de-açúcar, posteriormente insurgiu a necessidade de ocupação do interior da colônia. O processo de interiorização foi motivado por diversos fatores, no Nordeste, por exemplo, além de uma medida preventiva à invasão de estrangeiros, os entradistas chegavam ao interior à procura de pastagem para o gado, formando, assim, as grandes fazendas que em apenas um século já se estendiam por quase toda essa região. 
É esse cenário que consolida a ocupação do território cearense. A colonização do Ceará que ocorre de forma tardia, com mais de um século após a apropriação do Brasil, se estabiliza com a transformação do território indígena em uma área sob o controle das atividades pecuarista. De acordo com Pontes (2010, p. 30),

o modelo de ocupação do Ceará traçado pela pecuária extensiva deu-se, praticamente, no século XVIII, atendendo aos interesses dos pecuaristas, diante da necessidade de grandes extensões de terras para a atividade, influenciando o surgimento de conflitos e de manipulação/dominação política da classe trabalhadora.

Esse processo de ocupação, no entanto, não foi acompanhado de uma base legal que definisse os limites do território. Apesar de a propriedade privada já se constituir, nessa época, como um fator de relevante dominação política, não havia, no início, o interesse em estabelecer os limites territoriais, pois como o gado era criado solto, a delimitação das fronteiras poderia restringir a sua área de circulação e impedir a expansão de terras pelos pecuaristas. Além disso, mesmo com o relativo adensamento demográfico, não existia contingente populacional suficiente para ocupar todo o território a ser demarcado e fazer pressão para a regulamentação formal das fronteiras.

A elaboração da base legal que vai regular os limites territoriais não só no Ceará, mas também em todo Brasil, só vai acontecer na década de 1930, quando o IBGE elaborou o Decreto Lei n. 331, de dois de março de 1938, que discorre sobre a divisão territorial do país, estabelecendo os parâmetros para a criação e regulação dos municípios.

O recorte territorial cearense que se conhece hoje, incluindo os fenômenos que resultaram na incorporação ou no desmembramento de municípios, é ainda consequência desse processo de ocupação territorial. Durante muito tempo, o Ceará permaneceu como uma capitania subalterna a Pernambuco. As capitanias eram, então, a maior unidade administrativa que se dividiam em partes menores, denominadas comarcas; estas, por sua vez, se distribuíam em termos, que atualmente correspondem aos municípios.

Sobre essa divisão político-administrativa das capitanias hereditárias, Lima (2008, p. 119) afirma: 
As capitanias são de duas ordens: as principais como a de Pernambuco, e as subalternas como a do Ceará. Seus governantes, entretanto, na prática, têm os mesmos poderes; só diferem quanto ao título do governador: capitão-general e governador, nas principais, e capitão-mor ou governador nas subalternas. A capitania é, pois, a maior unidade administrativa, sendo dividido seu território em comarcas, e estas, por sua vez em termos (os municípios), com sede nas vilas ou cidades respectivas. Os termos se dividem em freguesias, a circunscrição eclesiástica que forma a paróquia, sede de uma igreja paroquial, também integrante da administração civil. E as freguesias, por fim, se desdobram em bairros, circunscrição de natureza mais imprecisa. (Grifos do autor)

Cada termo ou município eram dirigidos pelas Câmaras Municipais que, no início da colonização, eram dotadas de relativa autonomia para governar, possuindo, assim, funções fazendárias, político-administrativas, judiciais e de polícia.

No caso do Ceará, muitos termos deram origem às vilas e, nesse sentido, Lima (2008) aponta o adensamento da população como um dos fatores responsáveis por estimular a criação delas nesse estado.

Em certas áreas, especialmente nas ribeiras, a chegada de novas levas de colonos e povoadores ao nosso território acarretava, necessariamente, aumento do banditismo, da vagabundagem e da criminalidade pelos sertões adentro, delitos contra os quais a Coroa sempre procura exercer a maior coerção. Estando, pois, a população agrupada nas vilas, tornava-se muito mais fácil exercer o efetivo controle sobre ela. (2008, p. 120)

O adensamento da população foi condicionado pelo surgimento de alguns núcleos de povoamento que se formaram sobre a influência das vias de comunicação do Ceará colonial, também conhecidas como estradas das boiadas. Desenvolvidas a partir do litoral e ao longo dos cursos dos rios, essas vias ampliaram as transações comerciais e incitaram o povoamento da capitania.

Alguns cruzamentos e principais pontos de parada das vias de comunicação deram origem às fazendas de gado que também tiveram papel importante no povoamento da Capitania. Espelhada pelo sertão, a fazenda de gado se transformou em uma unidade econômica e social, visto que

foi a sede das sesmarias, da unidade familiar, da atividade produtiva e também onde se encontraram as condições propícias para os primeiros sinais de acumulação de renda no sertão. Além disso, 
foi sede da vida política local, de toda autarquia sertaneja e suas famílias, com poderes quase que absolutos, e da rede de mandos e desmandos que pautou a organização territorial. Cumpriu, ainda, o papel de defesa diante da população indígena ou perante outros sesmeiros na luta pela posse das terras. (Jucá Neto, 2012, p. 135)

Dos núcleos de povoamento oriundos das fazendas de gado e que estavam sob influência das estradas das boiadas, surgiu a maioria das vilas do Ceará que corresponderam a unidades territoriais com relativa autonomia política e administrativa.

Nesse contexto, durante o período colonial, foram instituídas 16 vilas (Figura 1), também conhecidas como células originais, pois deram origem aos 184 municípios cearenses.

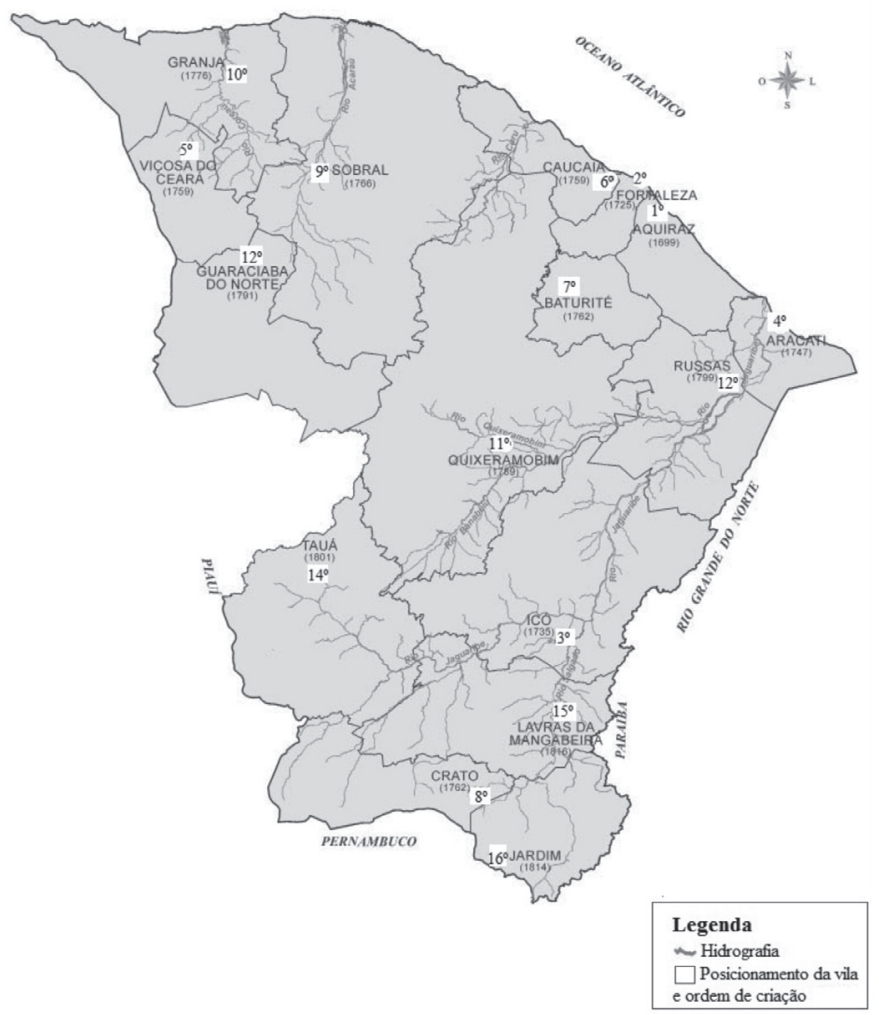

Figura 1- Localização das vilas criadas no Ceará entre 1699 e 1822. 
Depois do surgimento das vilas originais, a criação de municípios no Ceará foi se intensificando e passando por inúmeras transformações, através da incorporação e da desagregação de áreas. A intensa fragmentação do território cearense foi sempre motivada pela ação dos grandes proprietários de terras: os senhores das fazendas de gado e da produção de algodão que detinham em suas mãos o controle da política. Em síntese, as estruturas de ordem política e econômica que comandaram o Ceará durante muitos séculos ainda hoje exercem influências que se materializam nas formas clientelistas de poder e promovem as desigualdades socioterritoriais.

\section{A formação político-administrativa do Ceará e a fragmentação territorial}

A intensidade com que ocorrem as emancipações é, sem dúvida, uma consequência dos regimes políticos que vigoraram na história do país. Antes da Constituição de 1988, os municípios brasileiros sofreram intensas alterações no fluxo de desmembramento de seus distritos, uma vez que, desde o período colonial até o momento atual, ora os municípios estavam dotados de uma centralidade política, dependendo das decisões dos governos estaduais, ora se beneficiavam de uma autonomia que lhes concediam o direito de legislar sobre as questões de interesse locais.

O fato é que a compartimentação territorial, tanto no contexto local quanto no nacional, esteve ligada às estruturas de poder de quem tinha o controle sobre a terra e, consequentemente, o domínio político do Estado. Dessa forma, a criação de municípios, durante muito tempo, esteve condicionada aos interesses políticos e não ao bem comum da população.

Durante o período colonial, a divisão do território em capitanias hereditárias revelava uma estratégia de territorialização do poder que dispensava maiores investimentos da Coroa. Cigolini (2009, p. 90) afirma que "a imposição imediata da divisão do território foi a solução encontrada para estabelecer, sobre um espaço extenso e desconhecido, uma forma de governo. Governar, naquele momento, significava, sobretudo, manter o domínio".

Essa necessidade da Coroa de manter o controle e o domínio sobre a colônia exigia um poder centralizado; no entanto, isso não foi possível, pois a grande extensão territorial do país dificultava a fiscalização. A incapacidade de Portugal em controlar o território dotou as câmaras muni- 
cipais de relativa autonomia para governar, possibilitando a instalação de algumas vilas.

Pontes (2010, p. 24) aponta a pecuária como o principal fator responsável pela criação das primeiras vilas cearenses. Segundo a autora,

intensifica-se o criatório e o comércio do gado, bem como o beneficiamento da carne e do couro para o mercado interno, fatos que impulsionaram a formação das outras oito primeiras Vilas. Na bacia do Banabuiu - Quixeramobim prosperou a primeira Vila da região central do Estado, que foi a de Quixeramobim (1789); As bacias do Acaraú e do Coreaú tornaram-se os berços das vilas de Sobral (1766), Granja (1776) e Guaraciaba do Norte (1791); assim como a bacia do Rio Jaguaribe deu origem às vilas de Russas (1799) e Tauá (1801) na bacia do Salgado foram criadas as Vilas de Jardim (1814) e Lavras da Mangabeira (1816). Assim, em pouco mais de um século, entre 1699 e 1822, já havia uma relativa concentração populacional e de Vilas ao longo dos Rios Jaguaribe-Salgado, Acaraú e do Coreaú, com menor destaque para as bacias do Banabuiu-Quixeramobim.

No Período Imperial, perdura um centralismo provincial ainda mais acirrado que o existente na Colônia. Segundo Lima (2008, p. 121),

data de $1^{\circ}$ de outubro de 1828 a primeira lei orgânica dos municípios, qual seja, o Regimento das Câmaras Municipais, que as confina a funções meramente administrativas, subordinando-as aos Conselhos Gerais, aos presidentes da província e ao Governo Geral. É a então denominada "doutrina da tutela".

Mesmo sob essas condições, foram instaladas no Ceará 48 novas vilas desmembradas das 16 células administrativas originais, somando um total de 64 municípios.

Se durante a Colônia a pecuária havia fomentado a criação das vilas cearenses, durante o Império outros fatores somaram-se a essa atividade, como é o caso da seca no sertão, que se tornou motivo de barganha política. Os investimentos em obras públicas para amenizar os efeitos desse fenômeno climático, por um lado, intensificava a dependência local em relação ao governo central e, por outro, acirrava a disputa por territórios onde as obras contra a seca se faziam presente. Muitos autores afirmam que tal processo certamente motivou o desmembramento de muitos municípios.

Atrelado a isso, a economia algodoeira também teve forte influência nas emancipações municipais, pois permitiu uma série de investimentos em infraestrutura para facilitar a circulação de mercadorias nos princi- 
pais centros produtores de algodão, aumentando o contingente populacional e elevando muitos povoados à categoria de vilas.

Até esse momento, o poder de decisão sobre a agregação ou o desmembramento de municípios se manteve nas mãos daqueles que administravam a economia local, ou seja, os grandes proprietários de terras que controlavam a pecuária e a produção de algodão. A proclamação da República, mesmo provocando mudanças profundas na estrutura político-administrativa do país, não acarretou alterações significativas nesse quadro.

Apesar de a Constituição de 1891 ter decretado a autonomia municipal, os municípios ficaram cada vez mais subjugados ao poder dos coronéis. Sobre esse fato, Lima (2008, p. 123) afirma:

Os municípios são feudos dos coronéis, que mandam e desmandam. As províncias, ao contrário, passam a estado e se fortalecem sob a "política dos governadores". Nos estados aplica-se a "política dos coronéis". Estabelece-se nos dois casos um "sistema de compromissos" entre os governantes que atrela os chefes locais aos governadores e estes ao presidente da República. Os prefeitos são nomeados, conforme disponha a legislação estadual. As eleições são "a bico de pena”.

Nessas circunstâncias, o quadro territorial do Ceará passa a contar com 87 células administrativas, a partir da criação de 23 novos municípios. Pontes (2010) evidencia Baturité como o maior destaque desse período, em razão do avanço econômico resultante da produção algodoeira e do adensamento demográfico que o consagrou como alvo de fragmentação territorial. Somente no início da república, Baturité deu origem a cinco municípios: Aracoiaba, Aratuba, Guaramiranga, Mulungu e Pacoti.

O período que segue, de 1930 a 1963, é caracterizado por alternâncias e, no que condiz à centralização e à autonomia municipal, é também marcado por intensas mudanças no quadro político, econômico e social com relevantes impactos sobre o território e a população.

No intervalo de 1930 a 1936, os municípios estavam dotados de autonomia, tendo poder de decisão sobre as questões locais, mas essa situação acaba com o golpe do Estado Novo que, através da Constituição de 1937, faz com que os prefeitos sejam nomeados pelos governadores dos estados e a administração municipal seja controlada pelo Conselho Administrativo estadual. Essa situação perdura até 1945 quando é derrubado o Estado Novo e instaurada a Constituição de 1946, que devolve a auto- 
nomia aos municípios, permanecendo assim até 1963. Durante todo esse tempo, houve 54 desmembramentos no Ceará, o que perfaz uma total de 141 municípios.

O período correspondente à Ditadura Militar marca o auge da centralização do poder. A Constituição de 1967 liquida a autonomia municipal, fazendo com que os prefeitos voltem a ser nomeados pelos governadores dos estados. Durante essa fase, só foram criados municípios considerados relevantes à segurança nacional.

No Ceará, houve uma estagnação no processo de desmembramento e muitos municípios que foram criados entre 1958 e 1963 foram extintos. Podemos afirmar, então, que o único município criado nesse estado, durante a ditadura, foi Maracanaú, consolidado em 1983, quando o regime ditatorial já começava a entrar em colapso.

O fim da Ditadura Militar culmina em 1985, com a restauração da democratização política, consolidada pela convocação da Assembleia Constituinte que promulgou a Constituição Federal de 1988.

Essa constituição traz mudanças significativas para a situação municipal, já que, a partir dela, as células administrativas se consagram como autônomas, tornando-se ente federados, podendo legislar sobre os assuntos de interesses locais, através da elaboração de leis orgânicas. Outra mudança significativa é a maior participação dos municípios na partilha dos impostos federais e estaduais, além do fim da nomeação de prefeitos que passam a ser eleitos pelo voto direto.

Tais mudanças no regime político-administrativo do país soaram positivamente no quadro emancipacionista do Ceará; a partir desse momento 43 distritos foram elevados à categoria de município, totalizando atualmente 184 células administrativas.

A evolução da fragmentação territorial cearense sempre esteve condicionada a estratégias políticas de poder. Se antes da Constituição de 1988 fatores como a pecuária, o algodão e o crescimento da população eram suficientes para estimular a criação de municípios sob o controle e dominação dos grandes proprietários de terra, agora questões como a partilha da tarifa de impostos federais e estaduais e a possibilidade de levar elites locais ao poder são as novas estratégias que montam o cerne das emancipações político-administrativas. 
0 poder, o território e o estado no cenário das emancipações municipais

Sobre a ótica de delimitação territorial, o município pode ser conceituado como uma porção circunscrita de um estado que é administrativamente autônoma e governada por um prefeito e uma câmara de vereadores; no entanto, com base em Castro (2005), buscamos compreender o município sob uma perspectiva mais ampla:

Em primeiro lugar, este é um recorte federativo, com importante grau de autonomia - o que significa atribuições e recursos próprios -; em segundo trata-se de uma escala política, ou seja, um território político por excelência, e constitui um distrito eleitoral formal para vereadores e prefeitos e informal para todas as outras eleições com consequências importantes para a sociedade local e para o território; em terceiro, é no município que todos habitamos e exercemos nossos direitos, e deveres da cidadania, onde buscamos os serviços a que temos direito como cidadãos; onde votamos e candidatos são votados. Também é nele que são concretizadas as políticas públicas. (p. 135)

Como um recorte federativo dotado de autonomia administrativa, os municípios tendem a passar por constantes alterações nos seus limites territoriais, decorrentes do anseio de desmembramento dos distritos que os compõem. Esse processo é conhecido como emancipação político-administrativa e é definido por Pinto (2002, p. 8) como um

ato através do qual um distrito torna-se um município, ou seja, deixa de estar subordinado ao município de origem e passa a constituir um novo município, com governo próprio, Prefeito e Vice-prefeito Municipal, Câmara Municipal, Vereadores, leis próprias, arrecadação de tributos e impostos próprios.

No estado do Ceará, até 2013 havia aproximadamente 30 distritos aguardando a sansão do pedido de emancipação e, apesar de a Emenda Constitucional n. 15 de setembro de 1996 ter estabelecido políticas restritivas à criação de novos municípios, essa situação é ainda um reflexo da descentralização política ocasionada pela Constituição de 1988 que transferiu da União para os Estados o poder de decisão e a regulamentação das emancipações. De acordo com Tomio (2002, p. 65), "a autonomia institucional dos Estados, na elaboração da regulamentação e na decisão política, foi o fator preponderante para o ritmo diferenciado na criação de novos municípios". 
As alternâncias que ditaram o ritmo da criação de municípios desde o período colonial até a Constituição vigente, trabalhadas no tópico anterior, são a base para a compreensão das relações de poder que permeiam os processos de desmembramento municipal. Dessa forma, visando ao entendimento dessas relações, buscamos refletir sobre três elementos que estão incutidos no cerne do fenômeno de emancipação: o poder, o território e o Estado.

O poder é, em si, um conceito muito intricado, mas também de fundamental relevância para a compreensão dos processos que permeiam o quadro das emancipações político-administrativas, porque o anseio de desmembramento emana dos indivíduos e o indivíduo é, segundo Foucault (1979), um efeito do poder e, portanto, é também seu centro de transmissão.

Sobre essa lógica, o autor afirma:

O poder deve ser analisado como algo que circula, ou melhor, como algo que só funciona em cadeia. [...] O poder funciona e se exerce em rede. Nas suas malhas os indivíduos não só circulam, mas estão sempre em posição de exercer esse poder e de sofrer sua ação; nunca são o alvo inerte ou consentido do poder, são sempre centros de transmissão. Em outros termos, o poder não se aplica aos indivíduos, passa por eles. (Foucault, 1979, p. 184)

Assim, é possível entender que o poder está em todo lugar e para se manifestar basta que algum tipo de relação seja estabelecida. No caso das emancipações, as formas de poder ficam nítidas quando se consegue identificar todos os atores políticos envolvidos nesse processo, sejam estes as lideranças políticas locais, os eleitores, os parlamentares e o executivo estadual.

Se por um lado Foucault (1979) alega ser o indivíduo o centro de propagação do poder, Raffestin (1993), por outro, complementa esse pensamento afirmando ser a população a origem do poder. Ainda de acordo com a concepção desse autor, o poder está apoiado no tripé: população, território e recursos.

Considerando o que foi dito sobre a natureza do poder, será fácil compreender porque colocamos a população em primeiro lugar: simplesmente porque ela está na origem de todo poder. Nela residem as capacidades virtuais de transformação; ela constitui o elemento dinâmico de onde procede a ação. [...] O território não é menos indispensável, uma vez que é a cena do poder e o lugar de todas as 
relações, mas sem a população ele se resume a apenas uma potencialidade, um dado estático a organizar e a integrar uma estratégia. Os recursos, enfim, determinam os horizontes possíveis da ação. Os recursos condicionam o alcance da ação. (Raffestin, 1993, p. 58)

Com base nesses raciocínios, entendemos que, no processo de formação de novos municípios, a população corresponde aos indivíduos diretamente afetados nesse processo, o território é área que se quer emancipar e os recursos são as bases concretas que possibilitam a efetivação da emancipação.

Porém, a função do poder dentro do processo de criação de municípios não é denegar aos indivíduos o direito à vida social, pelo contrário, em muitos casos, quando os atores políticos se reúnem para reclamar a emancipação de determinados distritos, quase sempre são motivados pelo descaso dos municípios de origem com a demanda social de sua população. Esse entendimento, entretanto, se aproxima do pensamento de Foucault (1979) quando ele defende a tese de que a finalidade do poder não é reprimir e sim controlar.

O controle a que Foucault se refere é exercido sobre os homens para que se possa aperfeiçoar ao máximo a força de trabalho destes, tornando-os não só seres ativos, mas também dóceis, na medida em que se é estimulada uma diminuição da capacidade de revolta e de resistência à luta contra as condições impostas. Sobre estes preceitos, podemos concluir que o poder deve até não ser um instrumento de repressão, mas através das diversas formas de controle ele se revela um instrumento de manipulação.

Atrelado ao poder, o território se revela como uma instigante ferramenta de análise que reflete uma realidade complexa, em que se enseja, por isso, muitas tentativas de desvendá-lo.

O conceito de território não deve ser confundido com o de espaço ou de lugar, estando muito ligado à ideia de domínio ou de gestão de determinada área. Assim, deve-se ligar sempre a ideia de território à ideia de poder, quer se faça referência ao poder público, estatal, quer ao poder das grandes empresas que estendem os seus tentáculos por grandes áreas territoriais, ignorando as fronteiras políticas. (Andrade, 1995, p. 19)

Não podemos confundir território e espaço, porque este é, na verdade, anterior ao primeiro. O espaço é o todo dotado de partes que se torna território na medida em que é representado por um ator social. Em outras 
palavras, uma porção do espaço se transforma em território quando é modificada pelas redes e pelos fluxos estabelecidos pelos indivíduos para produzir distintas relações de poder.

Nesse sentido, Raffestin (1993, p. 144) define o território como "um espaço onde se projetou um trabalho, seja energia e informação, e que, por consequência, revela relações marcadas pelo poder. O espaço é a "prisão original”, o território é a prisão que os homens constroem para si”.

Souza (1995, p. 78) também concorda com esse raciocínio quando afirma que "o território [...] é fundamentalmente um espaço definido e delimitado por e a partir de relações de poder." Nesse sentido, podemos compreendê-lo como uma teia de relações sociais que são delineadas no espaço.

Outra noção de território que se mostra muito pertinente para o entendimento dos processos que giram em torno das emancipações é a defendida por Gottmann (2012), que discute o território sob uma ótica política, afirmando ser este a relação entre grupos politicamente organizados e o espaço. Segundo o autor, o "Território é um conceito político e geográfico, porque o espaço geográfico é tanto compartimentado quanto organizado através de processos políticos” (2012 p. 4).

Como um conceito político, o território organiza os indivíduos de uma comunidade em lugares separados por leis e governos próprios e, assim,

estabelece uma estrutura que serve aos interesses da comunidade que o habita. Qualquer organização de uma comunidade política terá que lidar com as estruturas internas de um pouco de variedade, um pouco de oposições e conflitos, requerendo tolerância mútua e um desejo de coexistência. (Gottmann, 1973, p. 148)

Junto com o entendimento de poder e de território, procuramos também compreender o que é o Estado, na tentativa de perceber como este interfere no cenário das emancipações político-administrativas. Com base nesse propósito, é necessário defini-lo a partir da correlação de três elementos essenciais: o território, o povo e o governo.

O território é o campo de atuação do Estado, é onde ele exerce o controle sobre o povo, através das diversas formas de governo. Sobre essa lógica, a concepção de Estado perpassa o simples ordenamento político e passa a refletir uma contradição, resultante de sua consolidação como instrumento de autoridade que surge mediada pela interação entre os in- 
teresses particulares e os da comunidade. Em outras palavras, isso significa que, "da mesma maneira que o trabalhador, mediante o trabalho, cria capital com os instrumentos de sua própria dominação, os seres humanos criam, na forma do Estado, os instrumentos para sua própria dominação" (Harvey, 2005, p. 78).

De acordo com o exposto, Bobbio (1987, p. 95) afirma:

A condição necessária e suficiente para que exista um Estado é que sobre um determinado território se tenha formado um poder em condição de tomar decisões e emanar os comandos correspondentes, vinculatórios para todos aqueles que vivem naquele território e efetivamente cumprido pela grande maioria dos destinatários na maior parte dos casos em que a obediência é requisitada, seja quais forem as decisões. Isto não quer dizer que o poder estatal não tenha limites.

Dessa forma, é quase impossível compreender como se estrutura os processos emancipatórios, sem entender o jogo de relações existente entre o poder, o território e o Estado, até porque, para Raffestin (1993, p. 152),

do Estado ao indivíduo, passando por todas as organizações pequenas ou grandes, encontram-se os atores sintagmáticos que produzem o território. De fato, o Estado está sempre organizando o território nacional, por intermédio de novos recortes, de novas implantações e de novas ligações.

\section{Considerações finais}

A ocupação tardia do Ceará ocorreu motivada pelas transformações dos territórios indígenas em territórios da pecuária. À luz desse processo, em menos de um século de apropriação, grandes fazendas já se espacializavam por quase todo o sertão cearense.

Esse modelo de reocupação traçado pela pecuária extensiva, combinada posteriormente à atividade algodoeira, permitiu aos fazendeiros se apropriar de grandes propriedades de terras; no entanto, esse processo não foi acompanhado de uma base legal que definisse os limites político-administrativos do território.

O recorte territorial do Ceará que se conhece hoje, incluindo os fenômenos de incorporação e desmembramento de municípios e os conflitos que decorrem desse processo, é ainda consequência desse modelo de ocupação do território cearense. 
Sobre essa lógica, chegamos à conclusão de que a intensa fragmentação do território cearense é, em si, um fenômeno que foi sempre orientado pela ação dos grandes proprietários de terra que detinham o controle sobre a política e a economia. Esse foi, sem dúvida, um fator de grande relevância para evolução das 16 vilas existentes no século XVIII ao quadro atual de 184 municípios.

A intensidade dos processos emancipatórios que ocorreram no Ceará foi uma consequência dos períodos políticos que vigoraram na história do Brasil; por isso, ora as emancipações ocorriam com maior intensidade motivada pela autonomia dos municípios em legislar os assuntos locais, ora ocorriam com menor força em decorrência da centralização do poder, que deixava os municípios à mercê das decisões dos governos estaduais.

Assim, por trás do anseio de emancipação, há sempre fortes relações de poder e, para compreender esse fenômeno, é necessário o entendimento daquilo que corresponde ao poder, ao território e ao Estado. Ao poder, porque o anseio de desmembramento emana do indivíduo e, este como afirma Foucault, é o centro de dispersão do poder. Ao território, porque ele rege as questões referentes às demarcações político-administrativas e é o campo de atuação do Estado, e por fim, a este, porque é ele quem exerce o controle sobre os indivíduos.

\section{Referências}

ANDRADE, Manuel Correia de. A questão agrária no Brasil. São Paulo: IPESPE/ Hucitec, 1995.

BOBIO, Noberto. Estado, governo e sociedade: por uma teoria geral da política. Tradução de Marco Aurélio Nogueira. 9. ed. Rio de Janeiro: Paz e Terra, 1987.

CASTRO, Iná Elias de. Geografia e política: território, escalas de ação e instituições. Rio de Janeiro: Bertrand Brasil, 2005.

CIGOLINI, Adilar Antonio. Território e criação de municípios no Brasil: uma abordagem histórico-geográfica sobre a compartimentação do espaço. Tese (Doutorado em Geografia) - Universidade Federal de Santa Catarina, Santa Catarina, 2009. Disponível em: <https://repositorio.ufsc.br/bitstream/ handle/123456789/92531/268885.pdf? sequence=1>. Acesso em: 14 set. 2013.

FOUCAULT, Michel. Microfísica do poder. Tradução de Roberto Machado. Rio de Janeiro: Edições Grall, 1979.

GOTTMANN, Jean. The significance of territory. Charlottesville: University Press of Virginia, 1973. 
GOTTMANN, Jean. Evolução do conceito de território. Boletim Campineiro de Geografia, Campinas (SP), v. 2, n. 3, p. 523-545, 2012. Disponível em: <http://agbcampinas.com.br/ bcg/index.php/boletim-campineiro/article/viewFile/86/2012v2n3_Gottmann >. Acesso em: 9 out. 2013.

HARVEY, David. A produção capitalista do espaço. 2. ed. São Paulo: Annablume, 2005.

JUCÁ NETO, Clovis Ramiro. Os primórdios da organização do espaço territorial e da vila cearense: algumas notas. Anais do Museu Paulista, São Paulo, v. 20, n. 1, p. 133-163, 2012. Disponível em: <http://www.scielo.br/pdf/anaismp/v20n1/ v20n1a06.pdf>. Acesso em: 6 jan. 2014.

LIMA, Antônio Claudio Ferreira. A construção do Ceará: temas de história econômica. Fortaleza: Instituto Albanisa Sarasate, 2008.

PINTO, Georges José. Município, descentralização e democratização do governo. Caminhos de Geografia, Uberlândia (MG), v. 6, n. 3, p. 1-21, jun. 2002. Disponível em: <http://www.plataformademocratica.org/Publicacoes/10538.pdf>. Acesso em: 17 out. 2013.

PONTES, Lana Mary Veloso de. Formação do território e evolução políticoadministrativa do Ceará: a questão dos limites municipais. Fortaleza: IPECE, 2010.

RAFFESTIN, Claude. Por uma geografia do poder. Tradução de Maria Cecília França. São Paulo: Ática, 1993.

SOUZA, José Marcelo Lopes de. O território: sobre o espaço e poder, autonomia e desenvolvimento. In: CASTRO, Iná Elias de; GOMES, Pedro Cesar da Costa; CORREAA, Roberto Lobato (Orgs.). Geografia: conceitos e temas. Rio de Janeiro: Bertrand Brasil, 1995. p. 77-116.

TOMIO, Fabricio Ricardo de Limas. A criação de municípios após a Constituição de 1988. Revista Brasileira de Ciências Sociais, São Paulo, v. 17, n. 48, p. 6190, fev. 2002. Disponível em: <http://www.scielo.br/scielo.php?pid=S010269092002000100006\&script=sci_arttext $>$. Acesso em: 13 nov. 2013.

Vládia da Silva - Possui Graduação em Geografia pela Universidade Federal do Ceará e Mestrado em Geografia pela mesma Universidade.

Francisco Amaro Gomes de Alencar - Possui Graduação em Geografia pela Universidade Federal do Ceará. Mestrado em Desenvolvimento e Meio Ambiente. Doutorado em Sociologia. É professor do departamento de Geografia pela mesma Universidade. 